home. The code of practice produced by the working group will provide helpful guidance for health professionals in evaluating both advance statements and advance directives (refusals of treatment).

STUART HORNER Chairman

Medical Ethics Committee,

BMA,

London WC1H 9JP

1 Robertson GS. Making an advance directive. BMf 1995;310 236-8. (28 January.)

\section{Measles campaign}

EDITOR,-Towards the end of last year Elizabeth Miller $^{1}$ questioned whether Britain could match the results reported from measles immunisation campaigns in less industrialised countries. ${ }^{2}$ Ninety two per cent of $7 \cdot 1$ million children aged 5 to 16 were immunised in England through the measles and rubella immunisation campaign last November. Of the 172 district health authorities or NHS trusts, 37 achieved coverage of $>95 \%, 96$ achieved coverage of $90-95 \%, 31$ achieved coverage of $85-90 \%$, six achieved coverage of $80-85 \%$, and two achieved coverage of $<80 \%$.

Since the beginning of November last year the Public Health Laboratory Service has been able to use salivary antibody diagnosis to confirm measles in suspected cases. There were more than 100 positive reports in November and December last year. By 1 April this year, despite more than 800 samples having been tested, there had been only 21 confirmed cases, with full details available in 21 . Only one case occurred in a child whose age was covered by the campaign; that child's parents had withheld consent. All other cases were in children under the age for routine immunisation (9); children under 5 who had received one dose of measles, mumps, and rubella vaccine previously (3); or people aged 17 or over (8).

The purpose of the campaign was to prevent an expected epidemic. There can be little doubt that this has been achieved. Early indications are that in most areas transmission of measles among schoolchildren has been interrupted.

D M SALISBURY Principal medical officer $S$ D HORSLEY Department of Heal the London E1 8VG

Miller E. The new measles campaign. BMf 1994;309:1102-3.

(29 October.)
2 Measles elimination in the Americas. Bull Pan Am Health Organ 1992;26:271-4.

\section{Injury to child pedestrians}

EDITOR,-Ian Roberts concludes that the key to preventing injuries to children by motor vehicles is a change in transport policy. ${ }^{1} \mathrm{He}$ argues his case on the basis that the recent decrease in death rates probably reflects reduced exposure (fewer pedestrians), that personal characteristics are not strong predictors of injury, that education has had little effect on rate of injury, and that traffic management has been shown to work.

While transport policy is a key item on the agenda for preventing injury to pedestrians, other factors are also important, particularly until transport policy alters. These include children's knowledge, attitudes, and behaviour; parental attitudes to prevention of childhood injury, and towards giving permission for children's independent activities; enforcement of current traffic legislation; and optimum traffic management and environmental design based on current traffic policy. Whatever the ultimate solution, many of the factors that have been identified as contributing to accidents are behavioural. ${ }^{2}$ For example, most children are running across the road when an accident occurs ${ }^{3}$ and pedestrian fatalities are associated with alcohol drinking. ${ }^{2}$

Measuring the direct benefits of educational programmes is difficult. Nevertheless, accident records of the members of traffic clubs-children who received six monthly educational programmes on traffic safety-showed lower accident rates than for non-members (P Schioldborg, fifth congress of the international federation of pedestrians, Gello, Norway, 1976). Innovative educational programmes (and their evaluation) will continue to be necessary pending major environmental change.

Roberts equates pedestrians with walkers. For instance, he states that the higher rate of injury in children from poor families and those without access to a car may be because they walk more. Activities other than walking, such as playing in the street, are likely to be equally if not more important.

We are engaged in a study of children's risk behaviour and exposure to risks. Our preliminary observations indicate considerable differences in patterns of play by age, sex, and socioeconomic circumstances, and it would be surprising if such differences did not relate to injury rates.

While agreeing with the thrust of Roberts's editorial, we believe that a broad and balanced approach combining educational, regulatory, technological, and environmental components is essential to prevent childhood accidents. Narrowly focused health promotion has met with failure in other areas, and an integrated approach is essential. $^{23}$

HAMID SOOR Postgraduate student R S BHOPAI Professor of epidemiology and public health Department of Epidemiology and Public Health,

School of Health Care Sciences,

Medical School,

University of Newcastle,

Newcastle upon Tyne NE2 4HH

1 Roberts I. Injury to child pedestrians. BMf 1995;310:413-4. (18 February.)

2 Heraty MJ. Review of pedestrian safery research. London: Transport and Road Research Laboratory, Department of Transport, 1985.

3 Grayson G. The identification of training objectives: what shall we tell the children? Accid Anal Prev 1981;13:169-73.

4 Kelly MP, Charlton BG, Hanlon P. The four levels of health promotion: an integrated approach. Public Health 1993;107: 319-26.

\section{Success of NHS and Community Care Act 1990 for elderly people}

EDITOR,-Victoria Ajayi and colleagues suggest that the reforms relating to the NHS and Community Care Act 1990 have improved arrangements for discharging elderly people from hospital in the borough of Hammersmith and Fulham.' This is in contrast to an article by Tonks in 1993, which outlined major concerns regarding community care for frail and elderly people. ${ }^{2}$

We recently evaluated admissions to nursing homes from the community and from hospitals in Aberdeen since 1 April 1994 (one year after the reforms under the act were implemented) to assess whether selection bias occurred according to whether patients were funded by their local authority or privately. One hundred and nineteen patients were evaluated, of whom 69 were funded by local authorities and 50 privately. The investigators thought that only 81 patients were clearly appropriately placed. Furthermore, a significantly lower proportion of those with private funding were clearly appropriately placed $(28(56 \%) v$ $53(77 \%), P=0.017)$, and the Barthel score (a

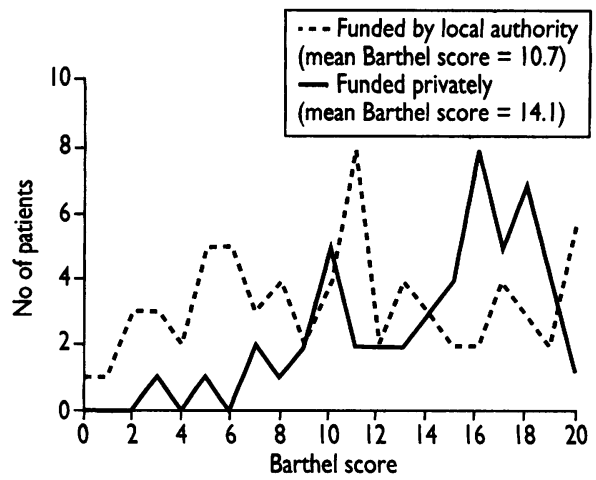

Barthel score in patients funded by their local authority or privately

measure of dependency - the lower the score the greater the dependency) was significantly higher in the privately funded group (mean (SEM) 14.1 $(0.56) v 10.7(0.68), \mathrm{P}<0.001$ on $t$ test, $\mathrm{P}=0.001$ on Mann-Whitney test) (figure).

In conclusion, selection bias seems to operate in favour of privately funded patients with a lower level of dependency; this disadvantages patients who require institutional nursing care but need help with funding from their local authority. Hence, for this group of patients the reforms under the community care act are not a success. More rigorous control of the assessment of patients requiring placement in a private nursing home is needed to obviate such bias.

$$
\begin{array}{r}
\text { D M NEWNHAM } \\
\text { Senior registrar } \\
\text { W R PRIMROSE } \\
\text { Consultant } \\
\text { D G SEYMOUR } \\
\text { Professor }
\end{array}
$$

Department of Medicine for the Elderly, Aberdeen AB9 2YS

1 Ajayi V, Miskelly FG, Walton IG. The NHS and Community Care Act 1990: is it a success for elderly people? $B M F$ 1994;330:439. (18 February.)

2 Tonks A. Community care fails the frail and elderly. BMf 1993;307:163.

\section{The Gulf war syndrome}

EDITOR,-Tony Revell's letter concerning the 200 personnel now assessed by the Ministry of Defence raises more questions than it answers.' Not the least is why it has taken over four years for the Ministry of Defence to start assessing these men and women when so many complaints were made soon after their return from the Gulf in 1991. Since $98 \%$ are (by the Ministry of Defence's own submission) suffering from something, perhaps Revell's medical service should have taken them more seriously in the first place.

The Ministry of Defence should beware, however, of assuming that the diversity of conditions listed implies no link. Three factors are common to all those personnel who have been assessed so far: all were in the Gulf; all were given a large number of inoculations, often in a hurry; and all took nerve agent pretreatment sets (pyridostigmine bromide tablets) as protection against biological and chemical warfare. It is at least possible that one causative link is damage to the immune systems of some individuals. Given that certain immunisation materials were prepared in a non-commercial environment (and details have been classified as secret, even to parliamentary questioners) and that the administration of these materials in the desert seems to have left a lot to be desired, this theory should be tested. If the immune systems of Revell and myself were compromised, even temporarily, we would be vulnerable to different bugs, yet the cause would be the same.

The high incidence of psychiatric conditions 